[Reprinted from Inorganic Chemistry, 10, $1202(1971)$.

Copyright 1971 by the American Chemical Society and reprinted by permission of the copyright owner.

Contribution from the Department of Inorganic Chemistry, UNIVERSITY OF NIJMEGEN, NIJMEGEN, THE NETHERLANDS

\title{
Copper(III) and Nickel(III) Complexes of Biuret and Oxamide
}

\author{
By J. J. BOUR, P. J. M. W. L. BIRKER, AND J. J. STEGGERDA*
}

Received September 11, 1970

Bis-biuretato complexes of $\mathrm{Cu}(\mathrm{II})$ and $\mathrm{Ni}(\mathrm{II}) \mathrm{K}_{2} \mathrm{M}(\mathrm{Rbi})_{2}$ (where $\mathrm{M}$ is $\mathrm{Cu}$ or $\mathrm{Ni}$, and $\mathrm{Rbi}$ is the dianion HNCONRCONH formed by deprotonation of the corresponding biuret, $R=H$ or alkyl) can be oxidized to $K M(R b i)_{2}$ in which the metal has the oxidation number III. Nmr, ir, and magnetic susceptibility studies of these compounds revealed that these ligands are bonded via their $\mathrm{N}$ atoms, most probably in a planar coordination around the metal. The oxidation oceurs in aqueous solutions at a potential of $0.50-0.65 \mathrm{~V}$ (relative to a saturated calomel electrode); in DMSO the reaction is a reversible oneelectron transfer at $E_{1 / 2}=-0.35 \mathrm{~V}$ as was shown by polarographic measurements. Two $\mathrm{H}_{2} \mathrm{O}$ or $\mathrm{RbiH}_{2}$ molecules can be bonded to the coordinated biuretate groups, most probably via $\mathrm{H}$ bridges. A bis-oxamidato complex $\mathrm{KCu}(\mathrm{HNCOCONH})_{2}$ could be prepared with analogous properties. The stabilizing influence of these ligands on the high oxidation states of the metals is thought to be due to the very strong electron-donating capacity of the deprotonated amine groups.

\section{Introduction}

In a previous short communication ${ }^{1}$ we have reported the preparation and the properties of bis-biuretato complexes of $\mathrm{Cu}$ (III) and $\mathrm{Ni}$ (III) with compositions of $\mathrm{KCu}(\mathrm{bi})_{2}$ and $\mathrm{KNi}(\mathrm{bi})_{2}$, respectively, wherein bi is the dinegative ion HNCONHCONH formed by deprotonation of biuret $\left(\mathrm{H}_{2} \mathrm{NCONHCONH}_{2}=\right.$ $\mathrm{biH}_{2}$ ). The further study of these compounds was seriously hampered by their extremely low solubility. We now succeeded in preparing analogous complexes derived from the alkyl-substituted biuretate ions (of the type HNCONRCONH) which are soluble in acetone, alcohol, and DMSO, allowing a more detailed study. With respect to the oxidation to a $\mathrm{Cu}$ (III) complex the dianionic form of oxamide (HNCOCONH $=$ oxam) behaves in the same way as the biuretate ion. We shall report here about the preparation and the properties of these compounds in which $\mathrm{Cu}$ and $\mathrm{Ni}$ have the uncommon oxidation state III. The specific influence of the ligands leading to a stabilization of these high oxidation states will be discussed.

\section{Experimental Part}

$\mathrm{K}_{2} \mathrm{Cu}(\mathrm{bi})_{2}, \mathrm{~K}_{2} \mathrm{Ni}(\mathrm{bi})_{2}$, and $\mathrm{K}_{2} \mathrm{Cu}(\text { oxam })_{2}$ were prepared according to known methods.,

Preparation of $\mathrm{KCu}(\mathrm{bi})_{2}$ - -(a) A solution of $\mathrm{K}_{2} \mathrm{Cu}(\mathrm{bi})_{2}$ was prepared by dissolving $2.2 \mathrm{~g}$ of biuret, $2.5 \mathrm{~g}$ of $\mathrm{CuSO}_{4} \cdot 5 \mathrm{H}_{2} \mathrm{O}$, and

(1) J. J. Bour and J. J. Steggerda, Chem. Commun., 2, 85 (1967).

(2) H. C. Freeman, J. E. W. L. Smith, and J. C. Taylor, Acta Crystallogr., 1, 407 (1961).

(3) M. M. Rising, J. S. Hicks, and G. A. Moerke, J. Biol. Chem., 1, 1 (1930).
$3 \mathrm{~g}$ of $\mathrm{KOH}$ in $25 \mathrm{ml}$ of water. When an excess of $\mathrm{K}_{2} \mathrm{~S}_{2} \mathrm{O}_{3}$ was added to this solution, the compound $\mathrm{KCu}(\mathrm{bi})_{2}$ precipitated immediately. The compound was filtered off, washed with hot water $\left(70^{\circ}\right)$, and dried in a vacuum desiccator.

(b) When the above-mentioned $\mathrm{K}_{2} \mathrm{Cu}(\mathrm{bi})_{2}$ solution was electrolyzed between $\mathrm{Pt}$ electrodes, $\mathrm{KCu}(\mathrm{bi})_{2}$ was precipitated on the anode. The anode potential, measured with an auxiliary saturated calomel electrode, was $0.50 \mathrm{~V}$. The compound was collected, washed with water, and dried.

(c) $\mathrm{KCu}(\mathrm{bi})_{2}$ was formed when air with some hydrogen chloride was bubbled through a suspension of $\mathrm{K}_{2} \mathrm{Cu}(\mathrm{bi})_{2}$ in benzene. On further study, uv irradiation, formerly reported to be necessary, ${ }^{1}$ appeared to be redundant.

Anal. Calcd for $\mathrm{KCu}(\mathrm{bi})_{2}$ : $\mathrm{Cu}, 20.85 ; \mathrm{K}, 12.84 ; \mathrm{C}, 15.76$; $\mathrm{H}, 1.97$; N, 27.58. Found: $\mathrm{Cu}, 20.95 ; \mathrm{K}, 12.72$; C, 15.61; $\mathrm{H}, 2.02 ; \mathrm{N}, 27.25$ (for a sample prepared according to method a, the other methods give analogous results).

Preparation of $\mathrm{KNi}(\mathrm{bi})_{2}$. - The procedures $a$ and $b$, as described for $\mathrm{KCu}(\mathrm{bi})_{3}$, but now starting with $\mathrm{NiSO}_{4}$, were possible. Method $b$ gave a very poor yield. The electrode potential, measured relative to saturated calomel electrode was $0.50 \mathrm{~V}$. Preparation according to procedure c was impossible. Anal. Calcd forK $\mathrm{Ni}(\mathrm{bi})_{2}$ : $\mathrm{Ni}, 19.57 ; \mathrm{K}, 13.04 ; \mathrm{C}, 16.02 ; \mathrm{H}, 2.02$; $\mathrm{N}, 28.01$. Found: Ni, 19.60; K, 13.10; C, 16.22; H, 2.13; N, 27.25.

Preparation of $\mathrm{KCu}(\mathrm{Rbi})_{2} \cdot 2 \mathrm{H}_{2} \mathrm{O}$. - The preparation of pure 3alkylbiuret appeared to be very difficult. The recipe of Weith 4 for the preparation of 3-phenylbiuret, modified to produce 3alkylbiuret, yielded a mixture of products, among which were 3- and 1-alkylbiuret. The separation of 3-alkylbiuret was very difficult and will be published elsewhere. In the next sections we give methods to prepare $\mathrm{KCu}(3-\mathrm{Rbi})_{2} \cdot 2 \mathrm{H}_{2} \mathrm{O}, \mathrm{R}=$ propyl, starting with pure 3 -propylbiuret and with the just mentioned reaction mixture.

(a) When $1 \mathrm{~g}$ of $\mathrm{KOH}$ was added to a solution of $0.5 \mathrm{~g}$ of $\mathrm{CuSO}_{4} \cdot 5 \mathrm{H}_{2} \mathrm{O}$ and $1 \mathrm{~g}$ of 3 -propylbiuret in $10 \mathrm{ml}$ of water, $\mathrm{Cu}$ -

(4) W. Weith, Ber., 10, 1844 (1877). 
(3- $\mathrm{Rbi})_{2}{ }^{2-}$ was formed. By electrolytic oxidation of this solution, $\mathrm{KCu}(3-\mathrm{Rbi})_{2} \cdot 2 \mathrm{H}_{2} \mathrm{O}$ precipitated on the platinum anode (anode potential $0.50 \mathrm{~V}$ relative to the saturated calomel electrode). The product was rinsed with water, dried, and dissolved in acetone. After evaporation of the acetone, the complex was crystallized from an alcohol or DMSO solution by adding chloroform and ether.

(b) With this same procedure but using the above-mentioned reaction mixture of 1 - and 3-propylbiuret (instead of pure 3propylbiuret), the interesting product $\mathrm{KCu}(3-\mathrm{Rbi})_{2}\left(1-\mathrm{RbiH}_{2}\right)_{2}$ was obtained. If a DMSO solution of this complex was exposed to moist air for $24 \mathrm{hr}, \mathrm{KCu}(3-\mathrm{Rbi})_{2} \cdot 2 \mathrm{H}_{2} \mathrm{O}$ could be precipitated by adding chloroform and ether. The preparation by oxidation of $\mathrm{K}_{2} \mathrm{Cu}(3-\mathrm{Rbi})_{2}$ with $\mathrm{K}_{2} \mathrm{~S}_{2} \mathrm{O}_{8}$ or with air was not possible.

Anal. Calcd for $\mathrm{KCu}(3-\mathrm{Rbi})_{2}\left(1-\mathrm{RbiH}_{2}\right)_{2}: \mathrm{Cu}, 9.35 ; \mathrm{K}$, 5.76; C, 35.36; H, 5.94. Found: $\mathrm{Cu}, 9.29 ; \mathrm{K}, 5.92 ; \mathrm{C}$, $34.50 ; \mathrm{H}, 6.40$. Calcd for $\mathrm{KCu}(3-\mathrm{Rbi})_{2} \cdot 2 \mathrm{H}_{2} \mathrm{O}: \mathrm{Cu}, 14.95 ; \mathrm{K}$, $9.20 ; \mathrm{C}, 28.26$; $\mathrm{H}, \mathbf{5 . 2 2}$. Found: $\mathrm{Cu}, 14.90 ; \mathrm{K}, 9.10 ; \mathrm{C}$, $28.15 ; \mathrm{H}, 5.28$.

Preparation of $\mathrm{KNi}(3-\mathrm{Rbi})_{2}\left(1-\mathrm{RbiH}_{2}\right)_{2}$ - - The same procedure as for the corresponding $\mathrm{Cu}$ complex could be used. The electrode potential was $0.65 \mathrm{~V}$ (relative to sce). Because the yield was very poor, the product could only be identified by its it spectrum being identical with that of the analogous $\mathrm{Cu}$ complex.

Preparation of $\mathrm{KCu}(\mathrm{oxam})_{2}$.-By electrolytic oxidation of a slurry of $3 \mathrm{~g}$ of oxamide in a solution of $1 \mathrm{~g}$ of $\mathrm{K}_{2} \mathrm{Cu}$ (oxam) $)_{2}$ in 50 $\mathrm{ml}$ of $0.1 \mathrm{~N} \mathrm{KOH}$ (electrode potential of $0.55 \mathrm{~V}$ (relative to sce), $\mathrm{KCu}$ (oxam) $)_{2}$ precipitated as a yellow product on the anode. The product could be purified from coprecipitated copper oxide by rinsing it fast with $1 N \mathrm{HCl}$, which dissolved the copper oxide much faster than the $\mathrm{KCu}(\mathrm{oxam})_{2}$. The complex was decomposed when exposed to light. Anal. Caled for $\mathrm{KCu}(\text { oxam })_{2}$ : $\mathrm{Cu}, 23.12 ; \mathrm{C}, 17.49 ; \mathrm{H}, 1.49 ; \mathrm{N}, 20.39$. Found: $\mathrm{Cu}, 23.01$; C, $17.40 ; \mathrm{H}, 1.48 ; \mathrm{N}, 20.95$. The preparation of the corresponding Ni complex appeared to be impossible.

Physical Measurements.-Magnetic susceptibilities were measured at room temperature using a standard Gouy-type balance. The results are given in Table I. Polarographic data were obtained with a Metrohm Polarecord E 261. DMSO was used as solvent with $0.05 M\left(n-\mathrm{C}_{4} \mathrm{H}_{9}\right)_{4} \mathrm{NClO}_{4}$ as supporting elec-
TABLE I

Magnetic Data at $25^{\circ}$, after Correction for Dlamagnetism ACCORDING TO FIgGIS AND LEWIS ${ }^{a}$

$\begin{array}{lcc} & \begin{array}{c}\text { Molar } \\ \text { susceptibility } \\ \times\end{array} & \begin{array}{c}\text { Effective } \\ \text { magnetic } \\ \text { moment, } \mathrm{BM}\end{array} \\ \mathrm{KCu}(\mathrm{bi})_{2} & 10 & \text { Diamagn } \\ \mathrm{KNi}(\mathrm{bi})_{2} & 2600 & 2.5 \\ \mathrm{KCu}(3-\mathrm{Rbi})_{2} \cdot 2 \mathrm{H}_{2} \mathrm{O} & 180 & \text { Diamagn } \\ \mathrm{KCu}(3-\mathrm{Rbi})_{2}\left(1-\mathrm{RbiH}_{2}\right)_{2} & 230 & \text { Diamagn } \\ \mathrm{KCu}(\mathrm{oxam})_{2} & 200 & \text { Diamagn }\end{array}$

a I. M. Kolthoff and P. J. Elving, "Treatise on Analytical Chemistry," Part I, Vol. 4, Interscience, New York, N. Y., 1963, pp 1778-1781.

TABLE II

Polarographic Data in DMSO Solutions (DMe Relative to Sce)

$\begin{array}{cc}E_{1 / 2}, \mathbf{V} & \text { Slope, }^{a} \mathbf{m V} \\ -0.35 & 65 \text { (reduction wave) } \\ -0.36 & 58 \text { (reduction wave) } \\ -0.33 & 54 \text { (oxidation wave) }\end{array}$

$\begin{array}{lll}\mathrm{RCu}(3-\mathrm{Rbi})_{2}\left(1-\mathrm{RbiH}_{2}\right)_{2} & -0.35 & 65 \text { (reduction wave) }\end{array}$

$\begin{array}{lll}\mathrm{KCu}(3-\mathrm{Rbi})_{2} \cdot 2 \mathrm{H}_{2} \mathrm{O} & -0.33 & 54 \text { (oxidation wave) } \\ \mathrm{K}_{2} \mathrm{Cu}(3-\mathrm{Rbi})_{2} & \end{array}$

a Slope of the plot of $\log \left[i /\left(i_{d}-i\right)\right]$ vs. $E$, which for a reversible one-electron transfer at $25^{\circ}$ is $58 \mathrm{mV}$.

$100 \mathrm{MHz}$. As external reference HMDS was used. The relevant nmr data are given in Table IV. Due to their insolubility no nmr spectra could be taken of the unsubstituted biuretato and oxamidato complexes. The data of the electronic spectra, measured with a Zeiss $P M Q$ II spectrophotometer, are given in Table V.

\section{Results and Discussion}

The oxidation of the biuretato complexes of $\mathrm{Cu}(\mathrm{II})$ and $\mathrm{Ni}(\mathrm{II})$ to the respective $\mathrm{Cu}(\mathrm{III})$ and $\mathrm{Ni}$ (III) compounds and of the $\mathrm{Cu}(\mathrm{II})$ oxamidato to the copper(III)-oxamidato complex is possible in alkaline solutions at oxidation potentials of $0.7-0.9 \mathrm{~V}$. This is

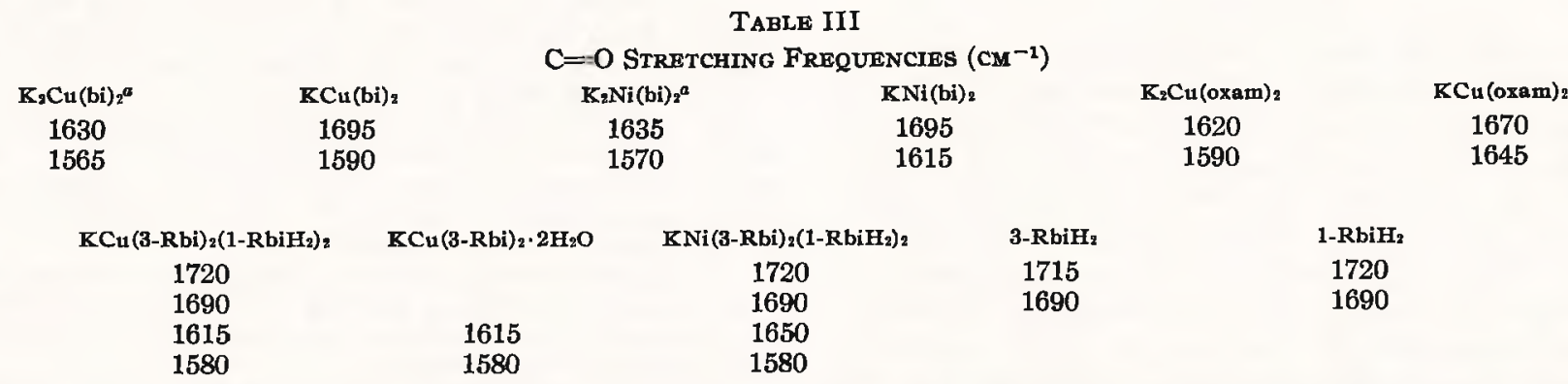

a B. B. Kedzia, P. X. Armendarez, and K. Nakamoto, J. Inorg. Nucl. Chem., 30, 849 (1968). b P. X. Armendarez and K. Nakamoto, Inorg. Chem., 5, 796 (1966).

TABLE IV

iH NmR Data of the Copper-Biuretato Complexes and Their Ligandsa

\begin{tabular}{|c|c|c|c|c|c|c|c|}
\hline$\tau^{b}$ & $-\mathrm{CH}_{\mathbf{3}}$ & $\mathrm{CH}_{2}$ & $\mathrm{~N}-\mathrm{CH}_{2}$ & $\mathrm{~N}_{1}<\frac{\mathrm{Cu}}{\mathrm{H}}$ & $\mathrm{N}_{1} \mathrm{H}_{2}$ & $\mathbf{N}_{1} \mathrm{HR}$ & $\mathrm{N}_{8} \mathrm{H}$ \\
\hline Biuret & & & & & $3.06(4)$ & & 1.28 (1) \\
\hline 1-Rbi & $8.94(3)^{c}$ & $8.36(2)$ & $6.77(2)$ & & $3.11(2)$ & $2.36(1)$ & $1.30(1)$ \\
\hline 3-Rbi & $8.96(3)$ & $8.32(2)$ & $6.28(2)$ & & $2.56(4)$ & & \\
\hline $\mathrm{KCu}(3-\mathrm{Rbi})_{2}\left(1-\mathrm{RbiH}_{2}\right)_{2}$ & $8.96(6)$ & $8.40(4)$ & $6.77(2) 6.36(2)$ & $4.42(2)$ & $3.06(2)$ & $2.29(1)$ & $1.20(1)$ \\
\hline $\mathrm{KCu}(3-\mathrm{Rbi})_{2} \cdot 2 \mathrm{H}_{2} \mathrm{O}$ & $9.00(3)$ & $8.42(2)$ & $6.36(2)$ & $4.40(2)$ & & & \\
\hline
\end{tabular}

a $\mathrm{R}=\mathrm{CH}_{3} \mathrm{CH}_{2} \mathrm{CH}_{2}$. Nitrogen atoms are numbered according to the structure $>\mathrm{N}_{2}-\stackrel{\text { CI }}{\mathrm{C}}-\mathrm{N}_{3}-{ }_{\mathrm{C}}-\mathrm{N}_{1}<.{ }^{b_{\tau}}=10+\left[\left(H_{\text {eomp }}-H_{\text {ref }}\right) /\right.$ $\left.H_{\mathrm{ref}}\right\}\left(10^{6}\right)(H=$ field strength; comp $=$ measured compound; ref $=$ reference $)$. ${ }^{\circ}$ The intensity ratios of the bands are given in parentheses.

trolyte. The potentials of the dropping mercury electrode were measured relative to a saturated calomel electrode. The data are listed in Table II. Infrared spectra of the solid compounds in $\mathrm{KBr}$ pellets were measured with a Perkin-Elmer 157 instrument. The $\mathrm{C}-\mathrm{O}$ stretching frequencies are listed in Table III. Nmr spectra in hexadeuteriodimethyl sulfoxide solutions were measured with a Varian HA 100 instrument operating at in agreement with the results of Levitzki and Anbar, ${ }^{5}$ who estimated the oxidation potential of the reaction $\mathrm{Cu}(\mathrm{bi})_{2}{ }^{2-} \rightarrow \mathrm{Cu}(\mathrm{bi})_{2}{ }^{-}+\mathrm{e}^{--}$to be between 0.85 and $1.07 \mathrm{~V}$. These high potentials are about the limit

(5) A. Levitzki and M. Anbar, Chem. Commun., 403 (1968) 
TABle V

Electronic Spectral Data $\left(\mathrm{Cm}^{-1}\right)^{a}$

\begin{tabular}{|c|c|}
\hline $\mathrm{K}_{2} \mathrm{~N}(\mathrm{bi})_{2}$ & $46,500(18,500)$ \\
\hline $\mathrm{KCu}(\mathrm{bi})_{2}$ & $41,000 \mathrm{~s}$ \\
\hline $\mathrm{KCu}(3-\mathrm{Rbi})_{2}\left(1-\mathrm{RbiH}_{2}\right)_{2}$ & $37,000(5000)$ \\
\hline $\mathrm{KCu}(3-\mathrm{Rbi})_{2} \cdot 2 \mathrm{H}_{2} \mathrm{O}$ & $37,000(5000)$ \\
\hline $\mathrm{K}_{2} \mathrm{Ni}(\text { oxam })_{2}$ & $29,000 \mathrm{~s}$ \\
\hline $\mathrm{KCu}(\text { oxam })_{2}$ & $28,700 \mathrm{~s}$ \\
\hline
\end{tabular}

$43,900 \mathrm{~m}$

a Extinction coefficients are given in parentheses. shoulder.

of what is possible in aqueous alkaline solutions. Slight modifications in the ligands cause the synthesis to fail; despite considerable effort, we did not succeed in preparing the oxamidato complex of $\mathrm{Ni}$ (III) and 3-phenylbiuretato and malondiamidato complexes of $\mathrm{Cu}(\mathrm{III})$ and $\mathrm{Ni}$ (III). We think that the specific influence of the biuretato and oxamidato ligands is primarily due to the strong electron-donating power of the deprotonated amine groups in these ligands. These cause a very high electron density on the metal ion, facilitating its oxidation. The $\mathrm{Cu}$ compounds are more easily oxidized than those of $\mathrm{Ni}$. The base strength of the ligands required for a stable oxidation product must be between an upper and a lower limit. When the base strength of the anion is very high, no deprotonation of the amine can occur; below a certain base strength the oxidation is impossible. Obviously the limits are also dependent on the redox as well as on the acidic properties of the solvent. Due to solubility problems however no other solvent than water could be investigated. Most amines, aliphatic or aromatic, are too weak acids to deprotonate, even in strongly alkaline solutions. The neighboring $\mathrm{C}-\mathrm{O}$ groups in biuret and oxamide apparently give a situation just between the critical limits. The failure to prepare the 3-phenylbiuretato complexes of $\mathrm{Cu}$ (III) and $\mathrm{Ni}$ (III) must then be ascribed to the electron-withdrawing capacity of the phenyl groups, which decrease the base strength of the ligand below the critical value for which oxidation of the metal is possible. Although deprotonation and complexation of malondiamide to $\mathrm{Cu}$ (II) was demonstrated by Rising, Hicks, and Moerke, $^{3}$ the impossibility to oxidize that complex is probably due to the lack of $\pi$ delocalization, which certainly also contributes to the stability of the biuretato and oxamidato compounds.

$\mathrm{Nmr}$ spectra of the copper-biuretato complexes show them to be coordinated via the $\mathbf{N}$ atoms (see Table III). This same can be concluded from the ir spectra of all $\mathrm{Cu}(\mathrm{III})$ and $\mathrm{Ni}(\mathrm{III})$ complexes, using the criterion given by $\mathrm{McLellan}^{6}$ and Kedzia. ${ }^{7}$ The oxamidato complexes of $\mathrm{Cu}$ (II) and $\mathrm{Ni}(\mathrm{II})$ are coordinated via $\mathrm{N}$ atoms as was established by the interpretation of ir spectra. ${ }^{8}$ Since the ir spectrum of $\mathrm{KCu}(\mathrm{oxam})_{2}$ resembles closely that of $\mathrm{K}_{2} \mathrm{Cu}$ (oxam) ${ }_{2}$, we think their structures to be similar (see Figure 1). $\mathrm{X}$-Ray crystal work has shown that the bis-biuretato complex of $\mathrm{Cu}$ (II) is planar. ${ }^{2}$ For the bis(biuretato)nickel(II) complex planarity was concluded on the basis of the diamagnetism and ir and electron spectroscopic

(6) A. W. McLellan and G. A. Melson, J. Chem. Soc. A, 137 (1967).

(7) B. B. Kedzia. P. X. Armendarez, and K. Nakamoto, J. Inorg. Nucl. Chem., 30, 849 (1968).

(8) P. X. Armendarez and K. Nakamoto, Inorg. Chem., s, 796 (1966).

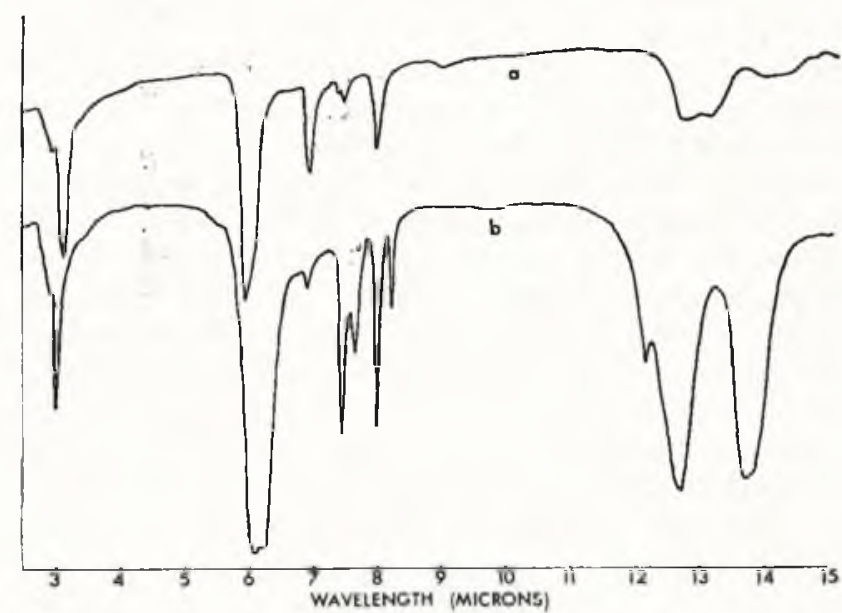

Figure 1.-Ir spectra of (a) $\mathrm{KCu}$ (oxam) $)_{2}$ and (b) $\mathrm{K}_{2} \mathrm{Cu}$ (oxam) $)_{2}$ in the $3-15-\mu$ region.

data. A detailed study of the ir spectra of the oxamidato complexes of $\mathrm{Cu}(\mathrm{II})$ and $\mathrm{Ni}(\mathrm{II})$ points out a planar structure for these compounds. ${ }^{8}$ We think the newly prepared $\mathrm{Cu}(\mathrm{III})$ and $\mathrm{Ni}$ (III) complexes also to be planar, a conclusion mainly based on the observed magnetic data, the $\mathrm{Cu}$ (III) complexes being diamagnetic and the $\mathrm{Ni}$ (III) complexes paramagnetic according to one unpaired electron spin.

The polarographic half-wave potentials of the oxida-

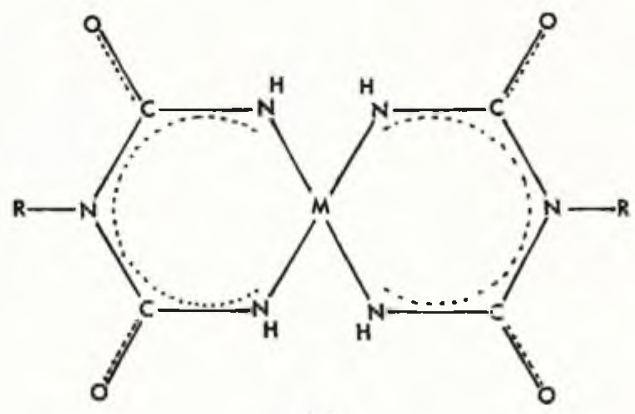

(a)

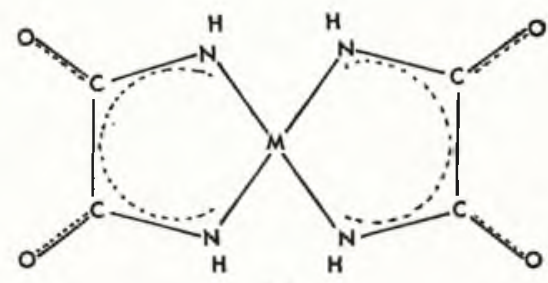

(b)

Figure 2.-The proposed planar structures of the biuretato (a) and oxamidato (b) complexes. 
tion and reduction waves of the $\mathrm{Cu}$ (III) and $\mathrm{Cu}$ (II) compounds, respectively, are practically identical. This fact, as well as the observed linearity of the log [i/ $\left.\left(i_{\mathrm{d}}-i\right)\right]$ vs. $E$ plot, reveals that both compounds can be interconverted by a reversible one-electron step ( $i_{\mathrm{d}}=$ diffusion current). This reversibility strongly suggests that both complexes have very similar structures, viz., planar four-coordination as illustrated in Figure 2.

The data of the electronic spectra of $\mathrm{KCu}(\mathrm{bi})_{2}$ and $\mathrm{KCu}$ (oxam) $)_{2}$, together with those of the isoelectronic $\mathrm{Ni}$ (II) species, are given in Table V. This similarity in these spectra give support to the idea of the structural similarity of these compounds. Regarding the structure of the $\mathrm{Ni}$ (III) complexes, however, no more evidence is available at the moment.

From a structural point of view these compounds are thus much like the series of $\mathrm{MN}_{4}{ }^{n}$ complexes reported by Balch and Holm. ${ }^{9}$ The ligand in these series (where $n$ can vary from $2-$ to $2+$ ) is $0_{-} \mathrm{C}_{6} \mathrm{H}_{4-}$ $(\mathrm{NH})_{2}$, which can exist in two forms of different oxidation state, viz., as the dianion of $o$-phenylenediamine and as $o$-benzoquinonediimine. This fact is strongly related to the characteristic properties of these series of metal complexes. Since different oxidation forms

(9) A. L. Balch and R. H. Holm, J. A mer. Chem. Soc., 88, 5201 (1966). of the dianions of biuret and oxamide are obviously not possibie, we think them to be representatives of a different class of ligands.

The structure of the interesting compounds KM(3-Rbi $)_{2}\left(1-\mathrm{RbiH}_{2}\right)_{2}$ is not definitely established. $\mathrm{Nmr}$ data (see Table IV) and ir spectra show that the 1propylbiuret is not deprotonated and not coordinated to the metal. The identical uv spectra and magnetic properties of $\mathrm{KCu}(3-\mathrm{Rbi})_{2} \cdot 2 \mathrm{H}_{2} \mathrm{O}$ and $\mathrm{KCu}(3-\mathrm{Rbi})_{2}-$ $\left(1-\mathrm{RbiH}_{2}\right)_{2}$ indicate also that there is no coordination of $1-\mathrm{Rbi}$ or $\mathrm{H}_{2} \mathrm{O}$ to the $\mathrm{Cu}$. Extensive $\mathrm{H}$ bridging is a characteristic feature of the chemistry of the biurets so we think that the two 1-propylbiuret molecules are $\mathrm{H}$ bonded to the biuretato ligands, probably via the 3-NH groups, because when these places are blocked by substituting an alkyl group, no extra biurets are found to be bonded to the complexes. The two $\mathrm{H}_{2} \mathrm{O}$ molecules in $\mathrm{KCu}(3-\mathrm{Rbi})_{2} \cdot 2 \mathrm{H}_{2} \mathrm{O}$ are probably bonded in the same way.

Acknowledgment.-The investigations were supported in part by the Netherlands Foundation for Chemical Research (SON) with financial aid from the Netherlands Organization for the Advancement of Pure Research. Besides, we wish to thank Mr. J. Diersmann for performing the analyses. 